\title{
EL PALAU MAJOR DE BARCELONA I EL CONVENT DE SANTA CLARA
}

\author{
Anna M. Adroer $i$ Tasis
}

El palau reial major de Barcelona, anomenat en els seus orígens palau comtal, va ser durant cinc-cents anys, o potser més, la residència principal dels nostres monarques. Tenim poques noticies sobre els seus orígens, però és indubtable que ja existia abans de la destrucció de la ciutat per Almansur (985) ${ }^{1}$.

Construit sobre la vella muralla romana, amb les seves torres exteriors i interiors, degué semblar un castell fortificat més que no pas un palau. Les primeres reformes de les quals tenim notícia, remunten al s. XI: s'aixecaren els dos ares que sostenen el pis de la sala de paraments (coneguda avui per Tinell) i la capella palatina sobre la vella fortificació romana.

En el transcurs del s. XII la residència reial fou ampliada: es construí un edifici a l'actual carrer dels Comtes, amb uns arcs semicirculars formant un claustre (edifici que avui forma part del Museu Marés).

Però les reformes més importants es realitzaren durant el s. XIV. A començaments d'aquest segle, Jaume II edificà la nova capella d'estil gòtic, convertí en sagristia i campanar una torre de la muralla i el 1359 Pere el Cerimoniós inicià les obres de la gran cambra de paraments.

1 Anna Maria Adroer I Tasis, El Palau Reial Major de Barcelona, Ajuntament de Barcelona, Delegació de Cultura, 1979, 2a ed. p. 15. 
Martí l'Humà també féu reformes al palau: construí una habitació al terrat, que ell anomenà «palauet de Bellvís», i diverses cambres, tant a planta baixa com al segon pis, i transformà el pati interior en un jardi.

Durant aquest segle XIV se'ns parla sovint del «palau de Santa Eulàlia del palau major, és a dir, se'ns cita un palau dintre d'un palau, ja que la denominació «palau» s'aplicava a les habitacions importants de la residència. La situació d'aquesta sala o palau de Santa Eulàlia, havia constituït sempre un enigma. Pels documents de l'època sabíem que es trobava davant de la catedral pel costat de la plaça de Sant Iu, però no ens era possible donar-ne el seu emplaçament exacte ${ }^{2}$. Un document trobat recentment ens ajuda a concretar-ho: el 1465 Mateu Creus, mestre de cases de la ciutat de Barcelona, rep l'encàrrec del capítol de la Seu de construir una plaça adavant el portal de Santa Eulàlia de la catedral sobre el qual està construït el campanar major». Deduïm que es tracta de la porta que ara s'anomena de Sant Iu, en el timpà de la qual una escultura representa la santa barcelonina amb la palma del martiri ${ }^{3}$. «La plaça serà edificada en les habitacions del palau del Rei que s'han d'enderrocar a causa de la construcció de la dita plaças ${ }^{4}$. El palau de Santa Eulàlia, doncs, estaria adossat a la paret posterior del Tinell, i ocuparia el solar que després es convertí en plaça de Sant Iu.

2 ADroer, Palau Major, p. 65.

3 Margarita Tinto Sala. *Notas para un catálogo de los Monumentos Con memorativos, Fuentes Histórico-Artisticas, Esculturas Decorativas de la Ciudad de Barelonas redactadas bajo la dirección de Federico Udina, en Cuadernos de Arqueologia e Historia de la Ciudad. Ayuntamiento de Barcelona, Museo de Historia de la Ciudad, núm. IX, 1965, p. 141, núm. 35.

4 AHPB - Notari Joan Ginebret, llig. 3

Tricesium sextum manuale comune

Die sabbati - XII januari.

1465, Barcelona dissabte 12 gener

Ego Matheus Creus magister domorum civis Barchinone gratis, etc. Per firmam ef solemnem stipulationem convenio et bona fide promitto bonorabili de. cano Capitulo ecclesie Barcbinone et vobis discretis Johanni Lambert et Narcisso Spanya presbiteris in ecclesia jamdicta benefficiatis suboperariis fabrice dicte ecclesie bic presentibus, quod dabo operam cum effectu omni exceptione remota quod extrabam seu extrahi faciam omnem terram sive scombra que egredietur de tota illa platea fienida ante portale Sancie Eulalie supra quod cloquear maitus dicte ecclesie est constructum. Que platea in presentiarum vel in futurum ediffi. canda est: videlicet illarum domorum palatii Regü que dirrui speransur propier dictam plateam edifficandam. Et haec promitto facerem continue ad Bartholo- 
En extingir-se la dinastia, la residència dels nostres monarques s'anà abandonant a poc a poc: l'any 1487 el rei Ferran deixà una part del palau a l'Inquisidor General de Catalunya com a residència del Tribunal del Sant Ofici. A més de la Inquisició, hi havia al palau una part destinada a Arxiu Reial i una altra al Tribunal del Mestre Racional. En la gran sala (Tinell) s'hi reunien els escrivans del Consell Criminal del Principat, i era tal la remor que s'hi feia, que la gent va acostumar-se a dir-ne sala del Borboll?'

Durant la guerra de Successió l'edifici quedà molt mal parat a causa dels bombardeigs, $\mathrm{i}$ ha estat precisament buscant unes notes sobre aquests fets que $m$ 'han arribat a les mans uns documents referents a les monges de Santa Clara, molt directament relacionades amb aquest palau, ja que obligades a abandonar el seu monestir del barti de Ribera, l'onze de setembre de 1714 (dia de l'assalt de les tropes franco-espanyoles a la ciutat), passaren a habitar durant molts anys el vell edifici de la plaça del Rei.

Alguns d'aquests documents són inèdits ${ }^{6}$ i abracen del $s$. XIII al s. XX. Abans de continuar, l'estudi del palau, doncs, explicarem

mei Mas lapisside noticiam sive cognitionem sub tali tamen conditione quod vos teneamini michi dare pro laboribus meis viginti florenos currentes sine dilatione etc. Quodque restituam missiones etc. Super quibus quidem missionibus etc. Ad baec nos Johannes Lambert et Nancissus Spanya suboperari ffabrice dicte ecclesie Barchinone convenimus et bona fide promitimus vobis Matheo Creus quod incontinenti et statim cum vos extraberemi seu extrabi faceremint dictam teram sive scombra a predictis domibus sive pariesibus ut predicitur dirruendis sitis ante dictum poriale dicte ecclesie dabimus et rrademus vobis pro stipendio et labo. ribus vestris viginti florenos currentes valenter undecim libre monete barchinone sine dilarione efc. Quodque restrifuemus missiones etc. Super quibus missioni: bus etc. Et probiis etc. obligamus pars parti et ad invicem scilicet Ego Matbeus Creus omnia et singula bona mea. Et nos dicti Johannes Lambert et Narissus Spanya bona et alia jura dicte ffabrice mobilia et immobilia etc. Et igitur etc. Ac. tum.

Testes etc. discreti Berengarius Salama in sede et Sthephanus

Caffabraga in ecclesie Sancri Justi presbiteri benefficiati.

Item cum alio instrumento dictus Matbeus Creus firmavit apocam de quinque li bris que fuerunt sibi scripte in tabula cambii sive depositorum civitatis Barchino. nem insolutum promata dictorum viginti florenorum sibi dari promissorum cau. sa extrahendi terrem sive scombra.

5 G. M. de Broca. Pere Corominas, J. Miret y Sans, snforme respecte a la propietat del Palau Major i instal lació de l'Arxiu de la Batllia del Reial Patrimo. nis, Anuari de l'Institut d'Estudis Catalans, 1908, pp. 32-35.

6 Agraeixo a la Comunitat de Sant Benet de Montserrat les facilitats donades a tota hora per consultar el seu arxiu, d'on provenen aquests documents. 
breument els orígens i la història d'aquest convent, que tant va sofrir les consequències de la guerra de Successió, i que fins fa pocs anys no ha pogut trobar un indret adequat a la seva vida contemplativa.

El monestir de Sant Anton i Santa Clara va ser fundat al barri de Ribera l'any 1237, en època de Jaume I, per monges clarisses vingudes de San Damiano (Italia) i per aquest motiu anomenades també monges de Sant Damià?.

El bisbe de Barcelona, Berenguer de Palou, els concedí moltes prerrogatives $^{8}$, i la facultat de construir un convent a la platja prop de Santa Eulàlia del Camp, i en aquesta ocasió ell mateix els adjudicà una capella (dedicada a Sant Anton) i una parcel.la de terreny ${ }^{9}$. El rei Jaume els féu donació d'un areny fins a les ones del mar, on plantaren l'hort ${ }^{10} \mathrm{i}$ de l'aigua que necessitessin ${ }^{11}$, i més tard (1365) ampliaren encara el patrimoni amb una donació de la reina Elionor, esposa de Pere el Cerimoniós ${ }^{12}$.

D'aquest monestir, primer de l'ordre a Catalunya, en sortiren algunes religioses per fundar altres convents, entre ells el de Pedralbes $(1326)^{13}$, i es diu que la reina Elisenda volgué que el claustre del monestir de Sarrià fos idèntic al de Santa Clara.

El seu nom originari era el de Sant Anton, i més tard cap al 1400 se li afegí el de Santa Clara. Com hem dit abans, era també conegut amb el nom de Sant Damià, i encara amb el de Sant Daniel, per estar situat al costat de la porta de Sant Daniel de la fortificació medieval del s. XIII, ja que en construir Jaume I la muralla entorn de la ciutat, hi va incloure, dintre, el citat monestir, a fi de que quedés ben protegit.

Malgrat que les monges eren franciscanes, a començaments del s. XVI, a causa de desavienences amb els frares franciscans, per raó d'observança i privilegis, $\mathrm{i}$ amb l'assentiment de Roma, decidiren passar-se a l'orde de Sant Benet.

Aquest convent era un dels més importants de la ciutat, i fou

7 SAlvador Sanpere y MiQuel, Toponimia anigua de Barcelona. La Rodalia de Corbera, 2 vols., Ayuntamiento de Barcelona 1890, vol. I, p. 27

8 A(rxiu) S(ant) B(enet) M(ontserrat) perg. 239 (Barcelona 29 marc 1239).

9 ASBM. Perg. 209 (Barcelona, 2 juny 1237).

10 ASBM. Perg. 352 (Barcelona, 25 juny 1246).

11 ASBM. Perg. 568. (Calatayud, 27 abril 1264).

12 ASBM. Perg. 832. (Barcelona, 11 gener 1369).

13 Joan Bassegoda Nonfll. Guia del Monestir de Pedralbes, Barcelona, 1978, p. 10. 
afavorit no solament pels monarques de la Corona d'Aragó ${ }^{14}$, sinó també molt considerat després pels reis castellans: sabem per exemple, que l'any 1599, després que Felip III i Margarida d'Austria es casessin a València, vingueren a Barcelona i visitaren oficialment el cenobi.

Com hem dit, el monestir passà moltes vicissituds. L'any 1691 durant la guerra dels francesos, les religioses es veieren obligades a abandonar-lo uns dies, fins que passés el perill. El 1713, a causa de la guerra de Successió al tron d'Espanya, l'exercit francoespanyol va assetjar la ciutat, i després d'un any de setge, de privacions i calamitats sens fi, l'onze de setembre de 1714 Barcelona va haver de capitular. La soldadesca va obrir una bretxa a la muraIla, pel costat del baluart de Sant Daniel i penetrà dintre el convent. Les monges no abandonaren mai el monestir i els soldats, en entrar-hi, trobaren l'abadessa i les altres religioses que no se n'havien mogut. Quan aquestes decidiren arreglar els desperfectes que la guerra havia causat a l'edifici, no els ho van permetre, i se les va comminar que l'abandonessin perquè el rei volia arrasar-lo i construir en aquell àmbit la Ciutadella $(1715)^{15}$.

Mentrestant, les religioses habitaven en cases de parents i amics, però no se les podia deixar perennement sense sostre, i es buscava un lloc per hostatjar-les. Es va pensar a donar-los per habitació i clausura l'edifici de la Llotja, i també el seminari del bisbe de Barcelona (l'actual Casa de Caritat) ${ }^{16}$, però els experts consideraren que no eren edificis aptes per a convent, i que s'hi haurien de fer obres molt costoses per poder-los habilitar. Es proposà també hostatjar-les a la Universitat Literària, a la Rambla, però consideraren el lloc massa sorollós per a unes monges de clausura. Finalment, volien destinar-los dues cases situades al carrer de Sant Pau, però tampoc aquest indret no era adient, perquè a les hortes de Sant Pau s'havien d'edificar uns carrers de nova planta, i si les monges s'hi establien perjudicarien el pla d'urbanisme ${ }^{17}$.

Decidiren donar-los l'antic palau major: ${ }^{2} \mathrm{El}$ palacio que llaman del Rey, la sala del Borboll y las piezas en que antes se juntaba la Audiencia... con todos sus derechos, pertinencias y

14 ASBM. Perg. 867 (Bareelona, 16 desembre 1400)

is ASBM. Doc, S/N (Barcelona, 1869).

16 JUAN B. Codina y Formosa. Gumersindo Alabart y SANS, Efemerides para la Historia del Seminario Conciliar de Barcelona. 2 vols, Barcelona, 1908; vol. I, El Seminario de Montealegre (1598.1772), p. 32 iss.

17 ASBM. Doc. S/N (Barcelona, 1715). 
dependenciass ${ }^{18}$. En la donació hi anava inclòs també el palau dels Virreis ${ }^{19}$ (l'edifici on ara hi ha l'Arxiu de la Corona d'Aragó), però no la capella de Santa Àgata, de la qual tenien cura els frares mercenaris ${ }^{20}$.

El dia 9 d'abril de 1718 varen prendre possessió del palau, menys de la sala del Borboll (l'actual Tinell) que anava, com hem dit, compresa dintre la cessió i que no posseirien d'una manera efectiva fins al 2 de març de 1720 , perquè era ocupada pels llits dels soldats i s'havia de buidar i netejar ${ }^{21}$.

Per l'abril de 1722 es començà la construcció de l'església dintre del Tinell $\mathrm{i}$ es feren altres obres: $\alpha . .$. se ejecute la Iglesia y otras obras que necesiten hacer dichas Religiosas en el Palacio que tienen contiguo al de la Inquisición... según lo convenido con los Ministros de ella y el Prior de los Mercenarios Calzados $\aleph^{22}$.

L'any 1789 les monges volgueren fer noves reformes, però els Inquisidors veïns seus no els ho permetien, i es veieren obligades a elevar una instància a Carles IV per tal d'obtenir el permís ${ }^{23}$.

Pel juliol del 1835 tingué lloc la revolució $\mathrm{i}$ crema de convents, i per ordre del Capità General les religioses es veieren obligades a abandonar $\mathrm{el}$ monestir. En tornar-hi, el 1855, no se'ls reintegrà $\mathrm{el}$ convent sencer, perquè a l'edifici dels Virreis s'hi havia d'instal-lar l'Arxiu de la Corona d'Aragó ${ }^{24}$.

La donació de 1718 les monges no la van considerar mai definitiva; sempre tenien l'esperança d'obtenir una subvenció per a construir un convent nou, ja que el patrimoni que els havien donat no es podia comparar amb el que els havien pres: els donaven uns edificis vells a canvi d'un monestir floreixent amb uns horts magnífics i un gran claustre.

Però després dels esdeveniments de l'any 1835, varen passar moltes vicissituds: varen viure en una casa de la Riera de Sant

18 ASBM. Docs. 542/1 (Madrid, 2 Novembre 1717) i 542/3 (Barcelona, 2 març 1720).

19 Els documents són confusos perquè, generalment, quan parlen del *Palau dit del Reis, es refereixen a l'edifici dels Virreis començat a construir a la mateixa plaça del Rei l'any 1547.

20 Buenaventura Bassegoda. La Real Capilla de Santa Águeda del Palacio de las Reyes de Anagón en Barcelona, Barcelona 1895, i també Narciso Feliu de la Peña y Farell, Anales de Catalunya, 3 vols, Barcelona 1709, vol. II p. 437.

21 ASBM. Doc. $542 / 2$ (Barcelona, 9 abril 1718).

22 ASBM. Doc. S/N (Barcelona, 12 abril 1722).

23 ASBM. Doc. 543. (Barcelona, 15 agost 1789).

24 ASBM. Doc. de la nota 15. 
Joan, varen tornar al palau el 1855, les expulsaren de nou el 1869 (Hisenda es va incautar del convent), i quan per R.O. de 2 gener 1872 els tornaren els seus béns ${ }^{25}$, varen considerar que s'havien d'acontentar amb aquests edificis i resignar-se, però el que no podien permetre era que no se'ls tornés l'antic palau dels Virreis i el mirador dit del Rei Martí, perquè ho consideraven una estafa. Varen batallar molt durant anys, i encara que mai no es donaren per vençudes, l'Arxiu no els el van tornar més. Solament varen poder obtenir el Tinell i els immobles del carrer Comtes de Barcelona núms. 6 i 8 . El núm. 10, o sia l'espai que els faltava per arribar a la Baixada de la Canonja, el compraren elles més tard.

Això les va perjudicar força, perquè durant molts anys no pogueren admetre cap novícia, perquè no tenien lloc. Les postulants suplicaven que les admetessin, brindant-se a dormir a terra si a causa del poc espai fos necessari, però ni d'aquesta manera no les podien acceptar.

Com que en aquella època el govern no donava permís perquè existissin ordes contemplatius, varen haver de decidir-se per alguna activitat: feren de planxadores i es dedicaren també a l'ensenyament. Pel desembre de 1863 l'Inspector d'Escoles passà a controlar-les $i$ ho trobà tot tan ben ordenat, que demanà a les monges que procuressin ampliar el local per poder admetre major nombre d'alumnes, i llavors elles feren construir dues habitacions sobre el terrat ${ }^{26}$.

Pel juliol de 1936, a causa de la guerra Civil, varen haver d'abandonar altra vegada el convent. La Generalitat se'n va incautar a fi que no es destruís. Quan l'any 1939 les religioses volgueren tornar, es trobaren amb la sorpresa que s'havia descobert el Tinell i s'havia començat a restaurar. (Perquè si bé per la documentació se sabia que la sala de Paraments del Palau Major havia d'existir, no es coneixia el seu emplaçament exacte, ja que en construir-s'hi dintre l'església de Santa Clara, s'havia tapat la seva estructura gótica).

L'Ajuntament decidí d'expropiar tot el que formava part de l'antic Palau ${ }^{27}$, (exceptuant la capella de Santa Àgata que havia seguit una vida i vicissituds a part la resta). La Comunitat de Santa Clara, prèviament requerida, presentà els títols de propietat

25 ASBM. Doc. S/N (Madrid, 2 gener 1872).

26 ASBM. Doc. nota 15.

27 ASBM. Doc. S/N (Barcelona, 10 juliol 1940). 
basant-se en la donació de 2 gener 1872 i el 3 maig 1941 el Municipi pagà l'adquísició dels immobles ${ }^{28}$. La part de palau corresponent al carrer Comtes de Barcelona es destinà a Museu Marés, i el Tinell passà a formar part del Museu d'Història de la Ciutat, que l'any 1943 s'inaugurà a la plaça del Rei.

Amb la suma rebuda, les monges ampliaren el convent de Santa Cecília de Montserrat i allí visqueren fins a l'any 1952. En aquesta data s'uniren amb les benedictines de Mataró, i juntes crearen un nou monestir en un vessant de la muntanya. És el monestir de Sant Benet, centre floreixent, on viuen avui més de cinquanta religioses.

28 ASBM. 2 docs. S/N. (Barcelona, 12 febrer 1941) i (Barcelona, 3 maig 1941). 